\title{
The Inhibition of Inflammasome by Brazilian Propolis (EPP-AF)
}

\author{
Juliana I. Hori, ${ }^{1}$ Dario S. Zamboni, ${ }^{1}$ Daniel B. Carrão, ${ }^{2}$ \\ Gustavo Henrique Goldman, ${ }^{3,4}$ and Andresa A. Berretta ${ }^{2,3}$ \\ ${ }^{1}$ Departmento de Biologia Celular, Molecular e Bioagentes Patogênicos, Faculdade de Medicina de Ribeirão Preto, \\ Universidade de São Paulo, FMRP/USP, 14049-900 Ribeirão Preto, SP, Brazil \\ ${ }^{2}$ Apis Flora Industrial e Comercial Ltda, Rua Triunfo, 945, 14020-670 Ribeirão Preto, SP, Brazil \\ ${ }^{3}$ Departamento de Ciências Farmacêuticas, Faculdade de Ciências Farmacêuticas de Ribeirão Preto, \\ Universidade de São Paulo, Avenida do Café s/n., 14049-900 Ribeirão Preto, SP, Brazil \\ ${ }^{4}$ Laboratório Nacional de Ciência e Tecnologia do Bioetanol-CTBE, Caixa Postal 6170, 13083-970 Campinas, SP, Brazil
}

Correspondence should be addressed to Gustavo Henrique Goldman; ggoldman@usp.br and Andresa A. Berretta; andresaberretta@hotmail.com

Received 11 January 2013; Accepted 18 February 2013

Academic Editor: Wojciech Krol

Copyright (C) 2013 Juliana I. Hori et al. This is an open access article distributed under the Creative Commons Attribution License, which permits unrestricted use, distribution, and reproduction in any medium, provided the original work is properly cited.

Propolis extracts have gained the attention of consumers and researchers due to their unique chemical compositions and functional properties such as its anti-inflammatory activity. Recently, it was described a complex that is also important in inflammatory processes, named inflammasome. The inflammasomes are a large molecular platform formed in the cell cytosol in response to stress signals, toxins, and microbial infections. Once activated, the inflammasome induces caspase-1, which in turn induces the processing of inflammatory cytokines such as IL-1 $\beta$ and IL-18. So, to understand inflammasomes regulation becomes crucial to treat several disorders including autoinflammatory diseases. Since green propolis extracts are able to regulate inflammatory pathways, this work purpose was to investigate if this extract could also act on inflammasomes regulation. First, the extract was characterized and it demonstrated the presence of important compounds, especially Artepillin C. This extract was effective in reducing the IL-1 $\beta$ secretion in mouse macrophages and this reduction was correlated with a decrease in activation of the protease caspase1. Furthermore, we found that the extract at a concentration of $30 \mu \mathrm{g} / \mathrm{mL}$ was not toxic to the cells even after a 18-hour treatment. Altogether, these data indicate that Brazilian green propolis (EPP-AF) extract has a role in regulating the inflammasomes.

\section{Introduction}

Over the last few decades, interest in natural medicines has been growing fast, leading to the discovery of new functional components and products that may help preventing or treating diseases. In this context, propolis extracts have gained special attention of consumers and researchers, due to their unique chemical compositions and functional properties $[1$, 2].

Propolis is a resinous material collected by bees (Apis mellifera L.) from exudates and buds of plants and mixed with wax and bee enzymes [1]. More than 300 compounds, among polyphenols, terpenoids, steroids, sugar, and amino acids, have been detected in raw propolis. Their abundance is influenced by geographical factors and botanical origins, as well as by collection season [3]. In this context, green propolis is only obtained from Brazil and its most important plant source is Baccharis dracunculifolia D.C. (Asteraceae) [4]. Several works reported biological activities to green propolis such as antiulcer [4, 5], anti-inflammatory [6], immunomodulatory activity (Machado et al., 2012, in press), antimutagenic [7], antifungal/antibacterial $[3,8]$, wound healing [9], and antiCandida albicans [10].

Considering all these biological properties of propolis, the anti-inflammatory effect is one of the most well known. Reis et al. evaluated the anti-inflammatory activity of propolis standardized extract on edema induced by carrageenan, dextran, and histamine. The extract showed effective results at $650 \mathrm{mg} / \mathrm{kg}$, significantly inhibiting the inflammatory process induced by carrageenan and histamine, but not by dextran [11]. The anti-inflammatory results were corroborated by Barros et al. (2007) that evaluated the effects in the models of 
gastric damage induced by ethanol, indomethacin, and stress in rats [4]. Paulino et al. demonstrated that green propolis extract, at low concentrations, induced anti-inflammatory and analgesic effects in mouse models, results obtained by oral or intraperitoneal administration [6]. Although propolis components responsible for the pharmacological activities are currently unknown, the flavonoids pinobanksin and kaempferol and the phenolic acid, artepillin $\mathrm{C}$ are strong candidates.

Some authors related that the biological activities of green propolis are mostly due to its high levels of prenylated $p$ coumaric acids derivatives, mainly 3,5-diprenyl-4-hydroxycinnamic acid (Artepillin C) [2]. In this context, Paulino et al. studied its anti-inflammatory effects, absorption, and bioavailability in mice model. In vivo results showed that Artepillin C reduced paw edema (38\% in 6 hours) and decreased the number of neutrophils during peritonitis and prostaglandin $\mathrm{E}_{2}$. Moreover, in vitro results demonstrated decrease in nitric oxide production and NF-kB activity, suggesting an anti-inflammatory effect of propolis extract [6].

Recently, a complex of molecules that is important in inflammatory processes, named inflammasome, has been described [12-16]. The inflammasomes are a large multimeric complexes formed in the cell cytosol in response to stress signals, toxins, and microbial infections $[15,16]$. After assembly of the multimeric complex, the inflammasome induces the activation of caspase- 1 protease. Once activated, caspase1 induces the processing of inflammatory cytokines, such as IL- $1 \beta$ and IL-18 $[16,17]$. Moreover, caspase- 1 activation also induces a type of inflammatory cell death named pyroptosis, thereby contributing to the generation of a proinflammatory response [18-20]. There are four inflammasomes described so far, distinguished by the receptor or NLRs (Nod-Like Receptors) involved in the complex: the NLRP1b [21, 22], the NLRC4/NAIP5 [23-25], the NLRP3 [26, 27], and AIM2 [28] inflammasomes.

The inflammasome activation is crucial for host defense to pathogens, but recent research has also found a role for the inflammasome in the pathogenesis of several diseases with an inflammatory component, such as type 2 diabetes, inflammatory bowel disease, and atherosclerosis [29-31]. These autoinflammatory diseases are clinical disorders that present recurrent inflammation due to abnormally increased inflammation mediated by cells of the innate immune system. However, the understanding of the inflammasomes regulation is still not clear and additional progress in this research field could contribute to new strategies in treating autoimmune diseases and their complication. Since propolis extract has been shown to regulate inflammatory pathways, it was investigated if the propolis standardized extract (EPP-AF) could also act on inflammasomes regulation.

\section{Material and Methods}

2.1. Collection and Preparation of Propolis Standardized Extract (EPP-AF). The Propolis Standardized Extract (EPP-AF) was produced from a blend composed by propolis raw material obtained from several sites of Brazil according to previous standardization (Patent no. PI 0405483-0, published in
Revista de Propriedade Industrial n. 1778 from 01/02/2005), the composition of the blend is majority constituted by green propolis. The extract was industrially produced and kindly provided by Apis Flora Company (Ribeirão Preto, SP, Brazil). Briefly, propolis was kept in $-20^{\circ} \mathrm{C}$ for $12 \mathrm{~h}$, ground to a fine powder in a blender. Then, it was extracted using hydroalcoholic solution (7:3), with dynamic maceration, during $72 \mathrm{~h}$ on room temperature, followed by percolation and a filtration process using, in the first step, the propolis biomass and secondly a 220 mesh stainless steel industrial line filter. Propolis extract obtained presents $11 \% \mathrm{w} / \mathrm{v}$ of dry matter and chemical composition standardized qualitatively and quantitatively by RP-HPLC.

2.2. Chemical Characterization of Propolis Extract. The propolis extracts were analyzed by HPLC using a Shimadzu apparatus equipped with a CBM-20A controller, an LC20AT quaternary pump, an SPD-M 20A diode-array detector, and Shimadzu LC solution software. A Shimadzu Shim-Pack CLC-ODS column $(4.6 \mathrm{~mm} \times 250 \mathrm{~mm}$, particle diameter of $5 \mu \mathrm{m}$, pore diameter of $100 \AA$ ) was used. The mobile phase consisted of methanol (B), and a solution of water-formic acid $(0.1 \% \mathrm{v} / \mathrm{v}), \mathrm{pH} 2.7(\mathrm{~A})$. The method consisted of a linear gradient of $20-95 \%$ of $\mathrm{B}$ over a period of 77 minutes at a flow rate of $0.8 \mathrm{~mL} / \mathrm{min}$. Detection was set at $275 \mathrm{~nm}$. For analysis it was used the standards caffeic, p-coumaric, and transcinnamic acids (Sigma-Aldrich, São Paulo, Brazil); artepillin C (Wako Pure Chemical Industries Co., Osaka, Japan), caffeic acid phenethyl ester (Sigma-Aldrich, São Paulo, Brazil), and aromadendrin- $4^{\prime}$-O-methyl ether, isolated by de Sousa et al. and kindly donated by the authors [32]. Methanol HPLCgrade was obtained from J. T. Baker and water was treated in Milli-Q water purification system. All other chemicals were of reagent grade and were used without further purification. Propolis extract was diluted with $5 \mathrm{~mL}$ of methanol (HPLC grade) in $10 \mathrm{~mL}$ volumetric flasks, subjected to sonication for $10 \mathrm{~min}$ and filled to volume with Milli-Q water. The samples $(n=3)$ were filtered through a $45 \mu \mathrm{m}$ filter before analysis.

2.3. Bacterial Strain. The bacterium used in this study was Lp02 strain of L. pneumophila [33]. The bacteria were cultured in MOPS buffered charcoal-yeast extract (CYE) agar (1\% yeast extract, 1\% 3-(N-morpholino) propanesulfonic acid (MOPS), pH 6.9, 3.3 mM L-cysteine, $0.33 \mathrm{mM} \mathrm{Fe}\left(\mathrm{NO}_{3}\right)_{3}, 1.5 \%$ Bacto agar, and $0.2 \%$ activated charcoal) and supplemented with thymidine $(100 \mathrm{mg} / \mathrm{mL})$ at $37^{\circ} \mathrm{C}$. Before infection, bacteria were resuspended in sterile water and diluted to a multiplicity of infection (MOI) of at least 10, based on optical density $\left(\mathrm{OD}_{600}\right)$.

2.4. Mice and Macrophage Preparation. C57BL/6 and Caspase $-1^{-/-}$mice were maintained and breed in Institutional Animal Facilities of the University of São Paulo. Bone Marrow Derived Macrophages (BMDMs) were prepared as previously described [34]. Briefly, bone marrow cells from femurs of adult mice were cultured for 7 days in RPMI 1640 containing $20 \%$ fetal bovine serum (FBS) and 30\% L-929 cell conditioned media (LCCM). Macrophages were replated one day prior to 
infection and maintained at $37^{\circ} \mathrm{C}, 5 \% \mathrm{CO}_{2}$, in RPMI 1640 media containing $10 \%$ FBS and 5\% LCCM.

2.5. Cytotoxicity Assay. The propolis cytotoxicity was assayed by ethidium bromide (EtBr) staining as described previously [20]. In this assay, $2.0 \times 10^{5} \mathrm{BMDMs}$ were plated on $13 \mathrm{~mm}$ glass coverslips in 24-well tissue culture dishes for $16 \mathrm{~h}$ at $37^{\circ} \mathrm{C}, 5 \% \mathrm{CO}_{2}$. The propolis was added on macrophages at 30,100 , or $300 \mu \mathrm{g} / \mathrm{mL}$ during $1,3,6$, or 18 hours. After the different times, the coverslips were inverted onto a $5-\mu \mathrm{L}$ drop of PBS containing $25 \mu \mathrm{g} / \mathrm{mL}$ EtBr and $5 \mu \mathrm{g} / \mathrm{mL}$ acridine orange. All cells were stained with acridine orange, whereas only cells with membrane pores allowed diffusion of EtBr into the cell. Pore-forming activity was measured as the percentage of BMDMs that stained positive with EtBr. Images were acquired using a Leica microscope (DMI4000B) with $10 \times$ and $40 \times$ objectives and analyzed using ImageJ software (TreeStar).

2.6. Cytokine Measurements. For cytokine determination, 2.0 $\times 10^{5}$ BMDMs were plated in 24-well plates for $16 \mathrm{~h}$ at $37^{\circ} \mathrm{C}$, $5 \% \mathrm{CO}_{2}$. For experiments with nigericin, gramicidin, and ATP, cells were pretreated with LPS $(1 \mu \mathrm{g} / \mathrm{mL}$, Sigma-Aldrich, São Paulo, Brazil) for $4 \mathrm{~h}$, treated with 30,100 , or $300 \mu \mathrm{g} / \mathrm{mL}$ of propolis for $1 \mathrm{~h}$ and then added nigericin $(20 \mu \mathrm{m}$, SigmaAldrich, São Paulo, Brazil), gramicidin $(100 \mu \mathrm{g} / \mathrm{mL}$, SigmaAldrich, São Paulo, Brazil), and ATP (5 mM, Sigma-Aldrich, São Paulo, Brazil) for additional $1 \mathrm{~h}$. For bacterial experiments, macrophages were treated with 30,100 , or $300 \mu \mathrm{g} / \mathrm{mL}$ of propolis for $1 \mathrm{~h}$ and infected with L. pneumophila at a MOI of 10 for additional $12 \mathrm{~h}$. The cytokine in the supernatant was measured by enzyme-linked immunosorbent assay (ELISA) with a mouse IL- $1 \beta$ kit (BD OptEIA) according to the manufacturer's instructions.

2.7. Flow Cytometry Analysis of Endogenous Caspase-1. For analysis of active caspase- 1 in BMDMs, $5.0 \times 10^{5}$ macrophages were plated in 48-well plates, BMDMs were stimulated with LPS (1 $\mu \mathrm{g} / \mathrm{mL}$, Sigma-Aldrich, São Paulo, Brazil) during $4 \mathrm{~h}$, treated with $30 \mu \mathrm{g} / \mathrm{mL}$ of propolis for $1 \mathrm{~h}$ and then added nigericin $(20 \mu \mathrm{m}$, Sigma-Aldrich, São Paulo, Brazil) for additional $1 \mathrm{~h}$. Before being stained, macrophages were removed with cold phosphate buffered saline (PBS). Macrophages were stained for $1 \mathrm{~h}$ with FAM-YVAD-fluoromethylketone (FAMYVAD-FMK; Immunochemistry Technologies) as recommended by the manufacturer. Data were acquired on a FACSCantoII (Becton Dickinson) and were analyzed using ImageJ software (TreeStar).

2.8. Colony Forming Unit Assay (CFU). To measure the number of bacteria in BMDMs, macrophage cultures were lysed in sterile water and cell lysates were combined with cell culture supernatant from the respective well. Lysates plus supernatants from each well were diluted in water, plated on CYE agar plates supplemented with thymidine, and incubated for 96 hours at $37^{\circ} \mathrm{C}$ for CFU determination.

2.9. Statistical Analysis. Statistical analyses were performed using GraphPad Prism, version 5.0, software. Data are
TABLE 1: Chemical composition of propolis standardized extract (EPP-AF) after four years and half on shelf life stability conditions $(\mathrm{mg} / \mathrm{g})(n=3)$.

\begin{tabular}{lcc}
\hline Standards researched & Average \pm SD & $\% \mathrm{CV}$ \\
\hline Caffeic acid & $0.244 \pm 0.001$ & 0.520 \\
p-Coumaric acid & $1.475 \pm 0.002$ & 0.115 \\
trans-cinnamic acid & $0.138 \pm 0.001$ & 0.903 \\
Aromadendrin & $0.423 \pm 0.001$ & 0.177 \\
Artepillin C & $3.690 \pm 0.016$ & 0.431 \\
\hline
\end{tabular}

SD: standard deviation.

$\%$ CV: coefficient of variation.

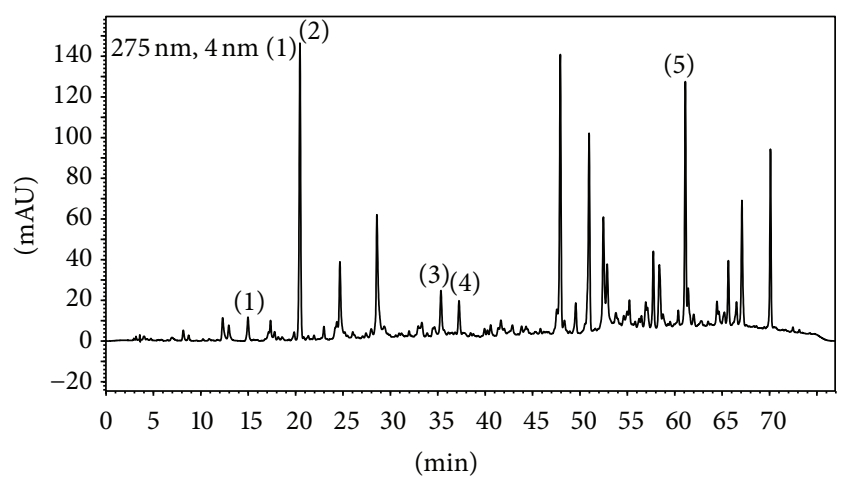

FIGURE 1: Fingerprint analysis of propolis alcoholic extract (EPPAF) with four years and half of shelf-life stability conditions. Chromatograms were plotted at $275 \mathrm{~nm}$, using RP-HPLC equipment with C18 (shim-pack, CLC-ODS $(\mathrm{M}), 25 \mathrm{~cm} \times 4.6)$ column and gradient elution with methanol and acidic water $(\mathrm{pH}=2.7)$. Chromatographic profile includes the compounds: (1) caffeic acid (around $15 \mathrm{~min}$ ), (2) p-coumaric acid (around $20 \mathrm{~min}$ ), (3) transcinnamic acid (around 35-36 $\mathrm{min}$ ), (4) aromadendrin (38 $\mathrm{min}$ ), and (5) Artepillin C (around 61-62 min).

expressed as the mean \pm standard deviation (SD) and statistical significance calculated by two-way analysis of variance (ANOVA), followed by Bonferroni posttest analysis. Differences were considered statistically significant if the $P$ value was $<0.05$.

\section{Results}

3.1. Chemical Characterization of Propolis Extract (EPP-AF). Propolis standardized extract (EPP-AF) was evaluated by HPLC and the fingerprint is represented on Figure 1. The results showed the presence of caffeic (1), p-coumaric (2) and trans-cinnamic (3) acids, the flavonoid aromadendrin (4) and the prenylated compound artepillin C (Figure 1) with respective values presented in Table $1(\mathrm{mg} / \mathrm{g})$. As a note, our results clearly showed that Brazilian propolis does not present CAPE (Caffeic Acid Phenethyl Ester), which has already been described having anti-inflammatory activities (Figure 2). Table 1 presents the quantitative characterization of propolis extract evaluated in the present work (Table 1). 


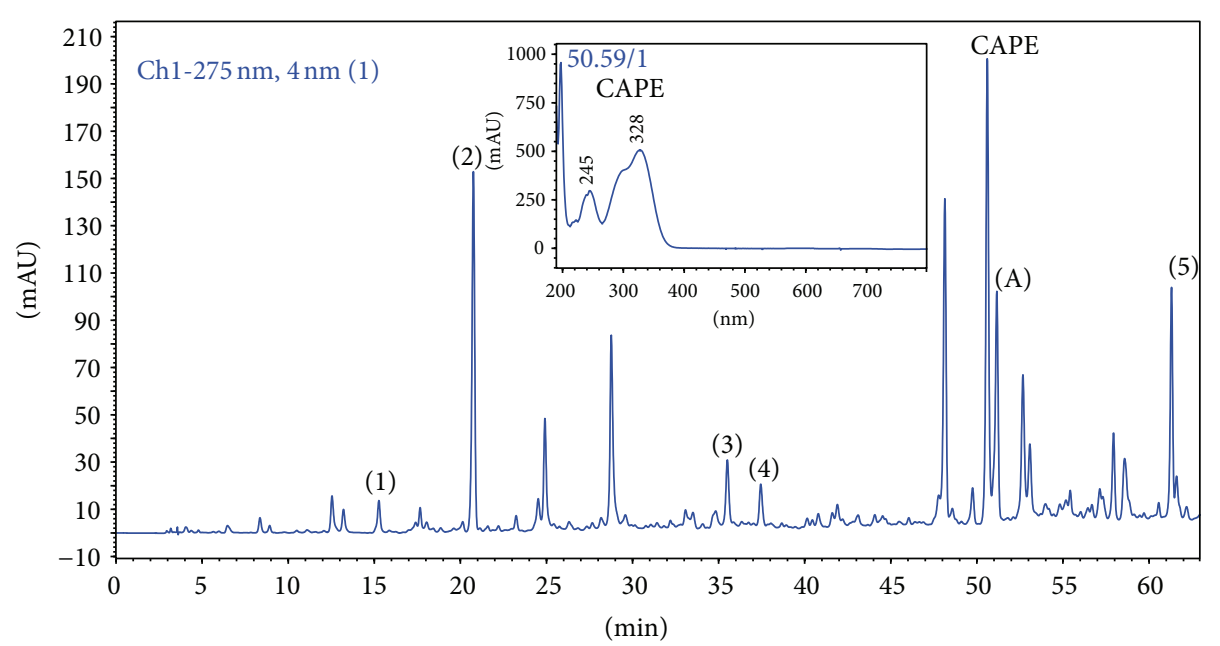

(a)

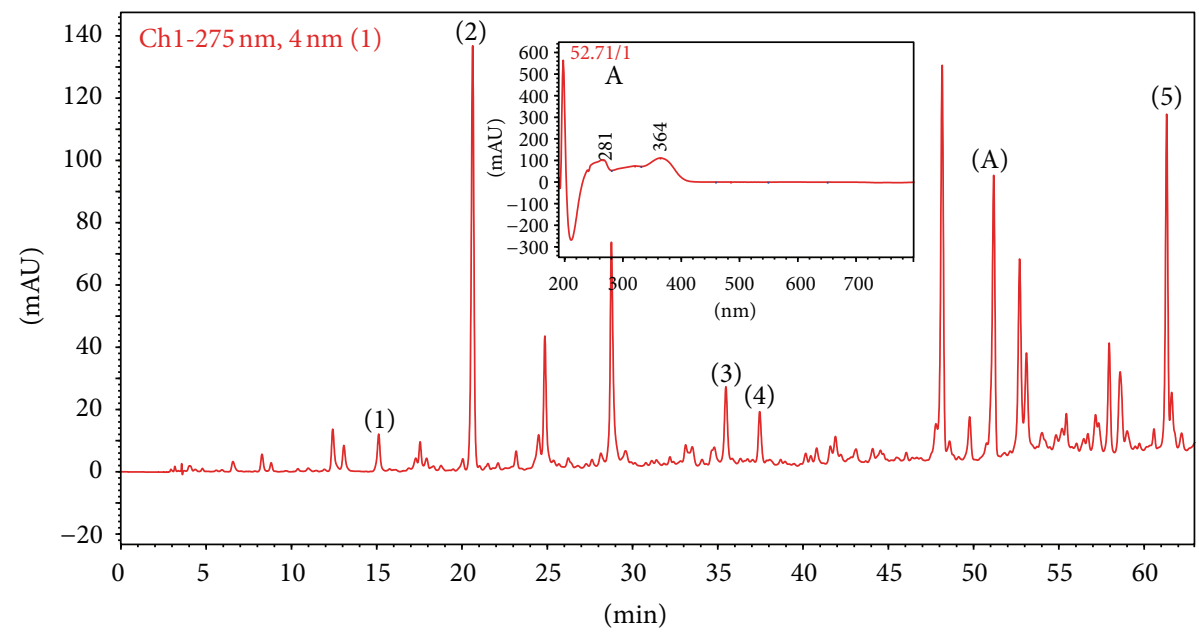
(1) Caffeic acid
(4) Aromadendrin
(2) $p$-coumaric acid
(5) Artepelin C
(3) Trans-cinnamic acid
(A) Unknown compound

(b)

FIGURE 2: Fingerprint analysis of propolis standardized extract (EPP-AF) in comparison with enrichment sample with CAPE. (a) Presentation of propolis standardized extract (EPP-AF) with CAPE $(100 \mu \mathrm{g})$ in the same chromatographic conditions used in Figure 1 , (b) propolis standardized extract showing a possible candidate to CAPE (A). To check the signs with similar retentions time of CAPE, UV spectra of CAPE and the candidate present in (b) were shown, demonstrating that propolis used does not present CAPE.

3.2. The Effect of Propolis on IL-1 $\beta$ Secretion by Macrophages. Several studies have reported the anti-inflammatory and immunomodulatory properties of Brazilian propolis $[3,4,35-$ 37]. Recently, the strong anti-inflammatory effect of propolis has been reported regarding the inflammatory response in different experimental models, such as local and systemic models employing mice (Machado et al., 2012, in press). In the present work, it was investigated if propolis was also related with the modulation of the IL- $1 \beta$, an essential cytokine involved in regulating inflammatory responses to both infectious and sterile injury [38-40]. To test this, we employed a canonical model with LPS and nigericin to induce IL-1 $\beta$ secretion by macrophages $[41,42]$. Thus, BMDMs from C57BL/6 mice were prestimulated with LPS during 4 hours, to induce pro-IL-1 $\beta$, and then treated with different concentrations of propolis $(30,100$, or $300 \mu \mathrm{g} / \mathrm{mL})$ for 1 hour, followed by nigericin treatment for additional 1 hour. We observed that LPS treatment or LPS plus propolis did not induce the IL-1 $\beta$ secretion. However, there was an expressive secretion of IL-1 $\beta$ by macrophages that were treated with LPS and nigericin (Figure 3(a)). Of note, this cytokine was extremely reduced in macrophages that were treated with propolis before the addition of nigericin (Figure 3(a)).

We investigated if the observed reduction of IL- $1 \beta$ was not due to a cytotoxicity caused by propolis to the macrophages. Thus, BMDMs were treated with 30,100 , or $300 \mu \mathrm{g} / \mathrm{mL}$ 


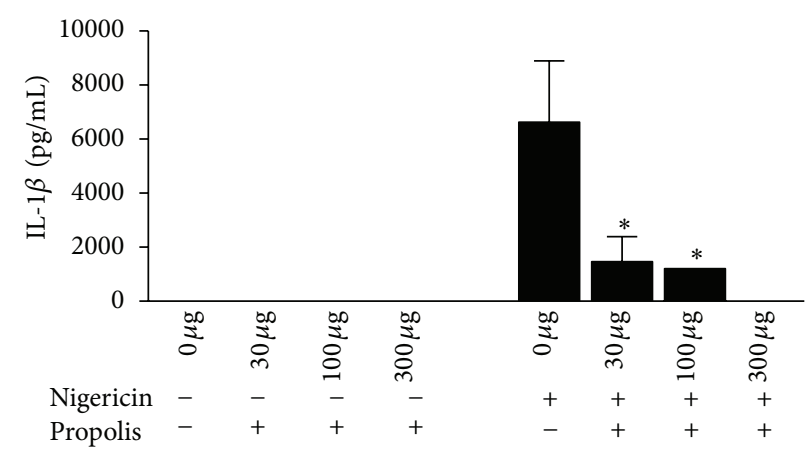

(a)
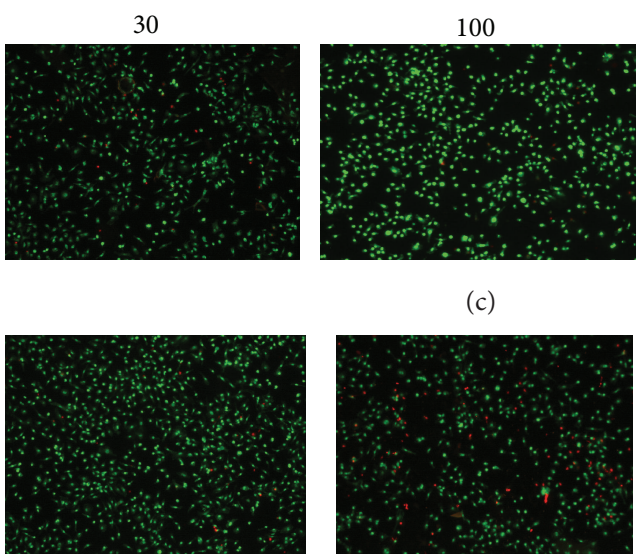

(d)
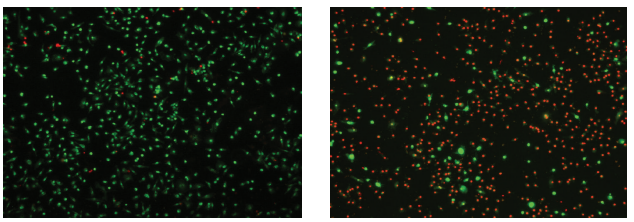

(e)
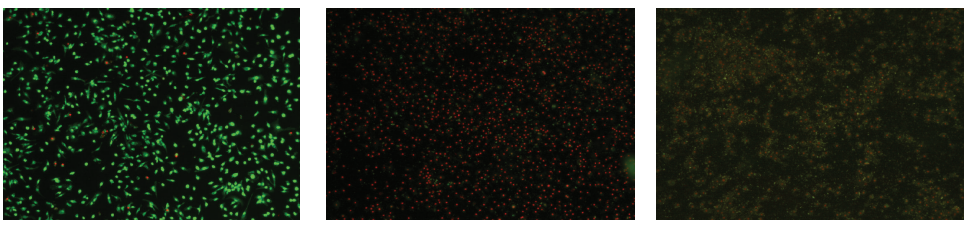

(f)
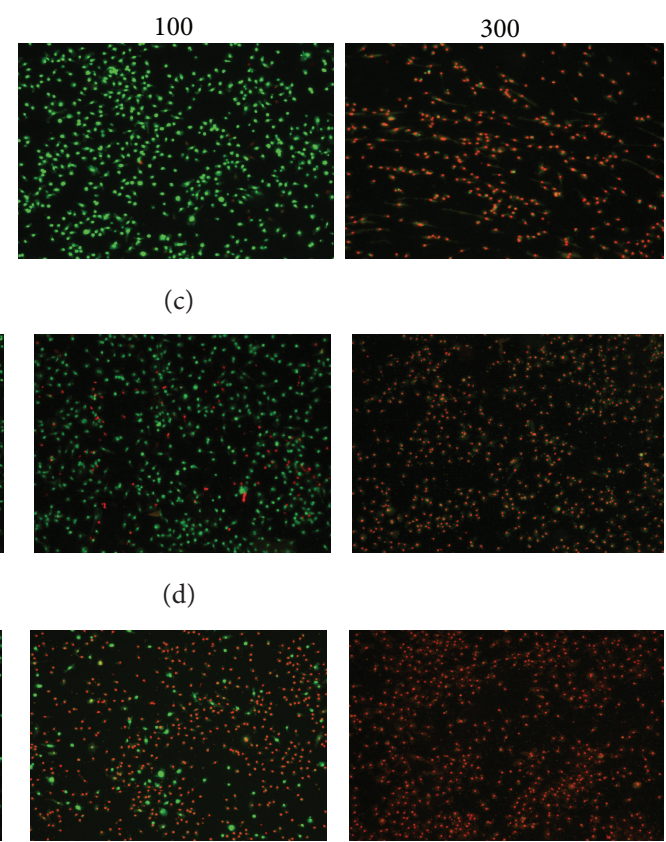

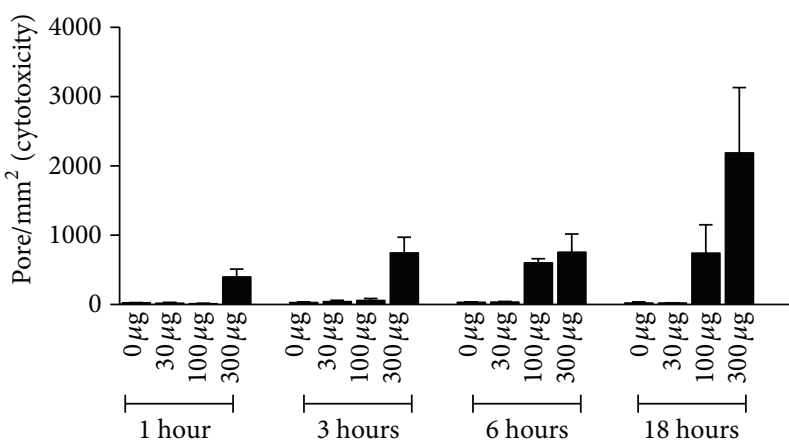

(b) FIGURE 3: Propolis standardized extract (EPP-AF) reduces the secretion of IL- $1 \beta$ by mouse macrophages. (a) BMDMs from C57BL/6 mice were
stimulated with LPS, pretreated or not with different concentrations of propolis extract and treated with nigericin for $1 \mathrm{~h}$. The cell supernatant was collected and levels of IL-1 $\beta$ were measured by ELISA assay. (b) Cytotoxicity assay of propolis. BMDMs from C57BL/6 mice were treated with 30,100 , or $300 \mathrm{ug} / \mathrm{mL}$ of propolis during $1 \mathrm{~h} \mathrm{(c),} 3 \mathrm{~h}(\mathrm{~d}), 6 \mathrm{~h}$ (e), and $18 \mathrm{~h}(\mathrm{f})$ and cells were analyzed by fluorescence microscopy. Data show average \pm standard deviation and an asterisk indicates a $P$ value of $<0.05$.

of propolis for $1,3,6$, and 18 hours and BMDM viability was analysed by ethidium bromide (EtBr) incorporation, using fluorescence microscopy. The intact membranes fail to internalize $\mathrm{EtBr}$, while cells containing pores or a rupture in plasma membranes become permeable to this dye [43]. This pore formation assay was performed by using EtBr in combination with acridine orange, a nonselective acidophilic green dye that stains both permeabilized and intact cells and therefore allows the determination of the percentage of cell death [44]. The results showed that after 1-hour treatment, the propolis concentrations of 30 and $100 \mu \mathrm{g} / \mathrm{mL}$ were not toxic to the cells, while $300 \mu \mathrm{g} / \mathrm{mL}$ was toxic to BMDMs (Figures 3(b) and $3(\mathrm{c}))$. By contrast, the use of propolis at $30 \mu \mathrm{g} / \mathrm{mL}$ was not toxic even after 18 hours of treatment (Figures 3(b), 3(c), 3(d), 3(e), and 3(f)), which led to the choice of this dose for further experiments. The data presented, therefore, indicate 
that propolis can modulate the secretion of the inflammatory cytokine IL- $1 \beta$ by BMDMs, a feature solely dependent on the inflammasome functions.

3.3. Propolis Inhibits the NLRP3 Inflammasome. The cytokine IL- $1 \beta$ is expressed as a proprotein (pro-IL-1 $\beta$ ) by immune cells and its activation requires a proteolytic processing in its mature form (IL-1 $\beta$ ) by the protease caspase-1. However, caspase- 1 is active only in the presence of activation signals, which in turn, takes place in the recently identified multimolecular complexes, called inflammasomes [14, 21]. In this regard, it was investigated if the modulation of IL- $1 \beta$ secretion by propolis was related with the modulation of the inflammasome. Since nigericin is a classical activator of caspase-1 via the NLRP3 inflammasome, we used nigericin to activate the canonical NLRP3 inflammasome. We monitored the endogenous caspase- 1 activation in BMDMs treated with LPS, nigericin and propolis by staining BMDMs with a fluorescent dye that binds with high affinity to the active form of caspase-1 $[45,46]$.

After the treatment with LPS and nigericin, a larger proportion of $\mathrm{C} 57 \mathrm{BL} / 6$ macrophages stained positive for active caspase-1, while a significant reduction was observed in macrophages that were pretreated with propolis (Figure 4(a)). Very few BMDMs deficient for caspase-1 $\left(\mathrm{Casp}^{-/-}\right)$presented FAM-YVAD staining after LPS and nigericin treatment, confirming that FAM-YVAD staining required caspase-1 (Figure $4(\mathrm{a})$ ). These results indicate that propolis interferes with inflammasome platform impairing the caspase- 1 activation by these complexes.

Finally, it was investigated the propolis action using different activators of the NLRP3 inflammasomes, such as ATP and gramicidin $[47,48]$. It was observed that propolis inhibits the IL- $1 \beta$ secretion in BMDMs treated with the different activators of the NLRP3 (Figures 4(b), 4(c), and 4(d)), thus supporting the findings that propolis can inhibit the NLRP3 inflammasome.

3.4. Propolis Reduces the $I L-1 \beta$ Secretion in Mouse Macrophages Infected with Legionella pneumophila. Genetic studies in mice can distinguish so far four different inflammasomes: NLRP1b, NLRP3, NLRC4, and AIM2. Since it was observed the effect of propolis on NLRP3 inflammasome, it was also examined its action in another well-described inflammasome: the NLRC4 inflammasome.

The NLRC4 inflammasome responds to gram-negative bacterial components such as flagellin and basal body Rod proteins present in bacterial type III secretion systems [23, 24, 49]. Consequently, intracellular pathogens expressing these factors, such as Salmonella typhimurium, Shigella flexneri, Pseudomonas aeruginosa, Burkholderia thailandensis, and Legionella pneumophila can activate the NLRC4 inflammasome $[15,23,24,26,50,51]$. In the present work, it was employed the gram-negative bacterium L. pneumophila to study the effect of propolis on NLRC4 inflammasome. Thus, BMDMs from C57BL/6 mice were treated with propolis for 1 hour and then infected with L. pneumophila for 12 hours. The results revealed that there was a reduction on IL- $1 \beta$ secretion by mouse macrophages that were infected but were pretreated with propolis (Figure 5(a)), suggesting that propolis can also modulate the NLRC4 inflammasome.

To investigate if the diminished amount of IL- $1 \beta$ found in BMDMs treated with propolis was not due to the antimicrobial activity of propolis on L. pneumophila, it was performed a CFU (colony forming units) assay in presence of propolis. We found that BMDMs treated with propolis and infected with L. pneumophila show no difference in the number of CFU found in macrophages in presence or absence of propolis (Figure 5(b)).

\section{Discussion}

Around $40 \%$ of medicines available nowadays were developed from natural sources: $25 \%$ from plants, $13 \%$ from microorganisms, and 3\% of animals. From 1981 to 2002, 60\% of medicines approved were natural products or obtained from these sources [52].

In this scenario, propolis is a very promising substance to be studied. It is a very complex compound from which many components have already been identified. Caffeic acid derivatives, flavonoids, and phenolic compounds, for instance, are usually found in many kinds of propolis $[9,32]$. On the other hand, other substances are specific to a certain type of propolis, such as CAPE (Caffeic Acid Phenethyl Ester), commonly present in European propolis [53] and Artepillin $\mathrm{C}$, a known exclusive biomarker of Brazilian green propolis $[32,54]$. Although the active compounds of propolis are still under discussion, there are a large number of biological effects attributed to some specific components present in propolis, especially CAPE and artepillin C. Therefore, in the present work, these substances and some representatives of caffeic acid derivatives were investigated in the Brazilian green propolis standardized extract (EPP-AF).

Nevertheless, it is also known that natural products possess a synergistic effect resultant of the mix of their compounds and if the active compounds are not yet identified, the total extract is regarded as the "active principle" and, in that case, the biomarker compounds are used for quality control. Because of that, it is crucial that the first step to testing any propolis formulation is to standardize a propolis extract according to a reproducible chemical profile.

The results demonstrated that the chemical standardization of propolis prepared here corroborated with the propolis profile presented in our previous work, which already revealed an effective anti-inflammatory activity [9].

Ansorge et al. showed that cytokines produced by monocytes/macrophages (IL-1 $\beta$, IL-12), as well as cytokines produced by Th2 type lymphocytes as IL-4, were found to be suppressed in the presence of propolis, whereas the production of TGF- $\beta 1$ produced by regulatory $\mathrm{T}$ cells was ascertained to be increased [55]. These effects were mediated, at least in part, by caffeic acid phenethyl ester (CAPE) $[55,56]$, hesperidin, and quercetin [55]. The compound CAPE has been described to possess anti-inflammatory, antiproliferative, anticancerogenic, and antioxidant effects. Moreover, it has demonstrated to decrease IL- $1 \beta$ in bleomycin-induced pulmonary fibrosis in rats model $[56,57]$. 

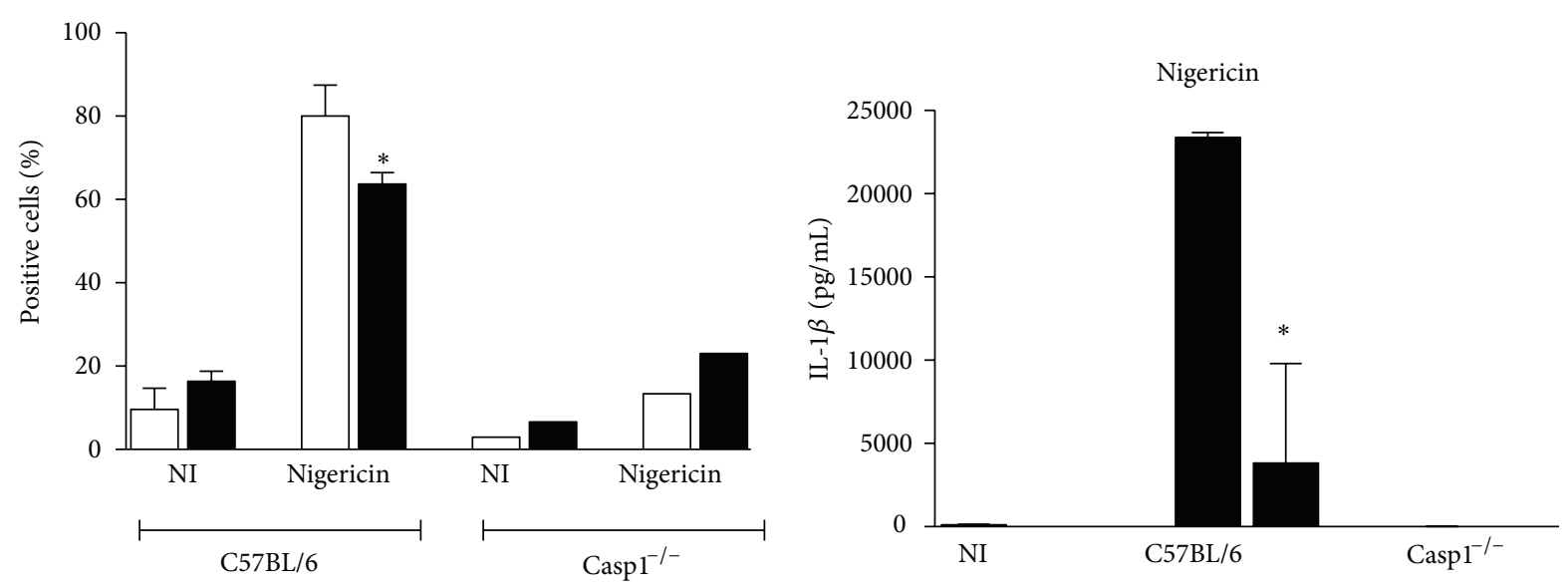

(a)

(b)
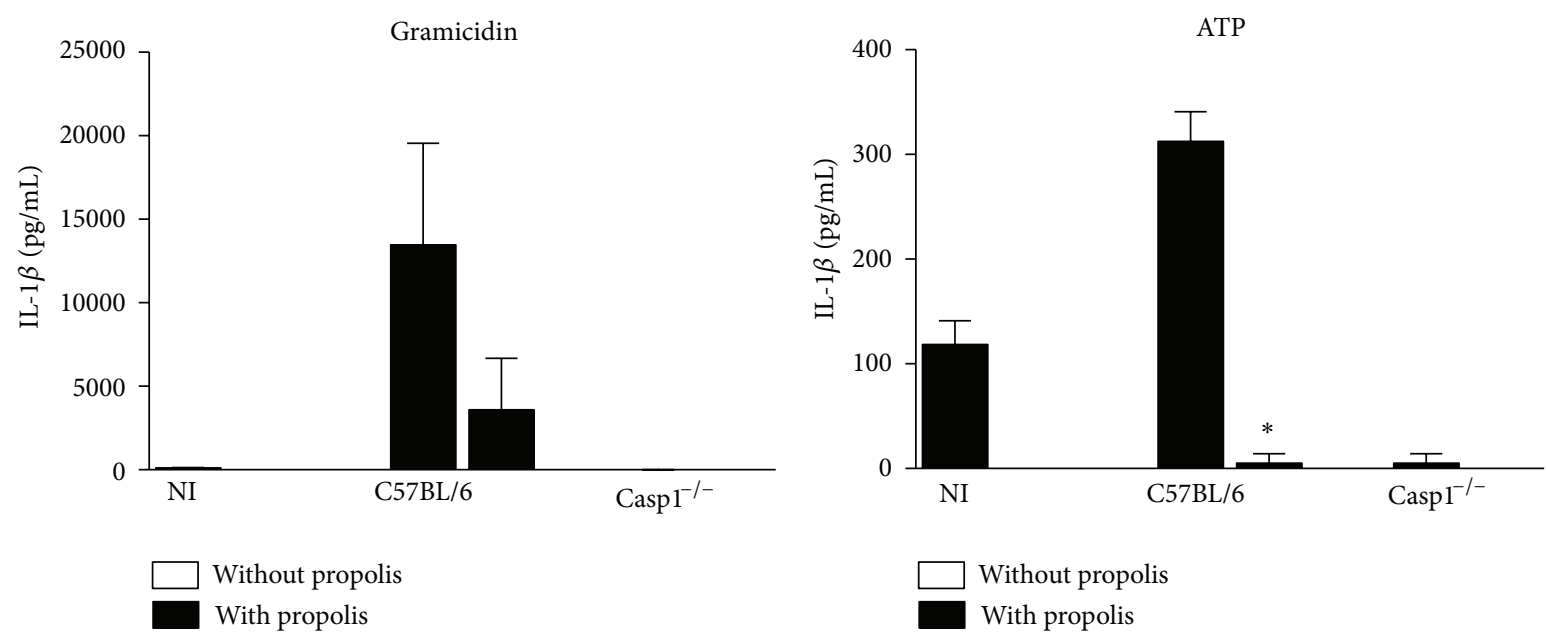

(c)

(d)

FIGURE 4: Propolis standardized extract (EPP-AF) inhibits the NLRP3 inflammasome. (a) BMDMs, $5.0 \times 10^{5}$ macrophages were plated in 48well plates, stimulated with LPS, pretreated or not with $30 \mathrm{ug} / \mathrm{mL}$ of propolis extract, and treated with nigericin for $1 \mathrm{~h}$. The cells were stained for $1 \mathrm{~h}$ with FAM-YVAD-fluoromethylketone (FAM-YVAD-FMK) and analyzed by Flow Cytometer on a FACS-CantoII. 30.000 events were acquired. (b) BMDMs from C57BL/6 and Caspase- $-^{-/-}$mice were stimulated with LPS, pretreated or not with $30 \mathrm{ug} / \mathrm{mL}$ of propolis extract, and treated with nigericin, Gramicidin (c), and ATP (d) for $1 \mathrm{~h}$. The supernatant was collected and levels of IL-1 $\beta$ were measured by ELISA assay. Data show average \pm standard deviation and an asterisk indicates a $P$ value of $<0.05$.

In the present work, it was verified that BMDMs pretreated with green propolis presented a reduction on IL-1 $\beta$ secretion after LPS and nigericin stimulation (Figure 3(a)). However, the results of chemical characterization of the green propolis standardized extract (EPP-AF) employed showed that CAPE is not present in the sample evaluated (Figure 2). In this regard, the next step that will be targeted is the evaluation of the standards found in the propolis extract used (Figure 1) in order to identify if one of them, specially the most interesting one, Artepillin C, is involved in the effect observed in the present work. Good results for Artepillin $\mathrm{C}$ are expected, fact suggested by the anti-inflammatory results presented for this compound by Paulino et al. [6]. We also verified that the reduction of IL-1 $\beta$ observed was not due to a cytotoxic effect of propolis on macrophages, since the cell viability assay with ethidium bromide showed that macrophages treated with $30 \mu \mathrm{g} / \mathrm{mL}$ of propolis did not present pores in the plasmatic membrane even after 18 hours of treatment (Figures 3(b), 3(c), 3(d), 3(e), and 3(f)).

IL-1 $\beta$ is a very important proinflammatory cytokine. Once secreted, IL- $1 \beta$ mediates a variety of local and systemic responses to infection, such as induction of fever, promotion of $\mathrm{T}$ cell survival, B cell proliferation, and antibody production and mediates the transmigration of leukocytes [58]. Nevertheless, this cytokine is produced as inactive propeptides that need to be processed in order to be secreted from immune cells. The secretion of mature form of IL- $1 \beta$ occurs only after its cleavage by the protease caspase- 1 and this process occurs in the presence of a molecular platform, named inflammasomes. Here we verified that modulation of IL- $1 \beta$ secretion by propolis was related with the modulation of the inflammasome, because there was a reduction on active 


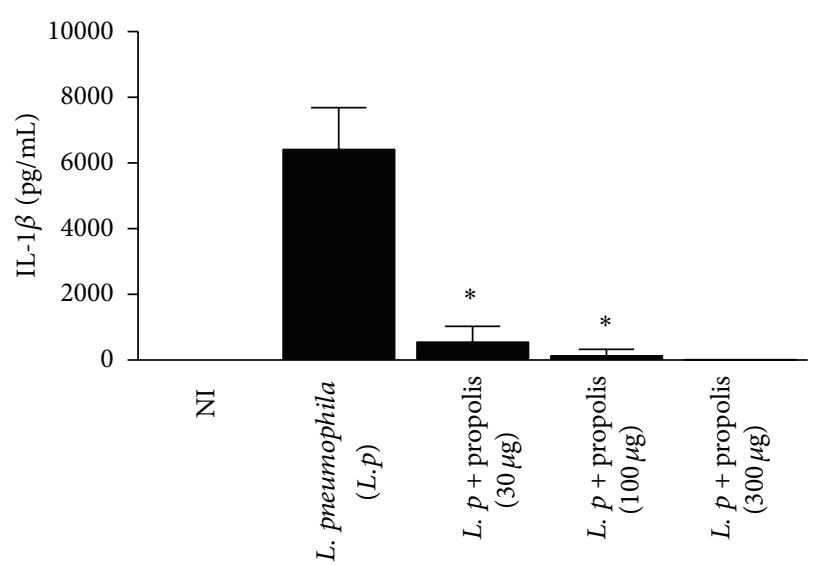

(a)

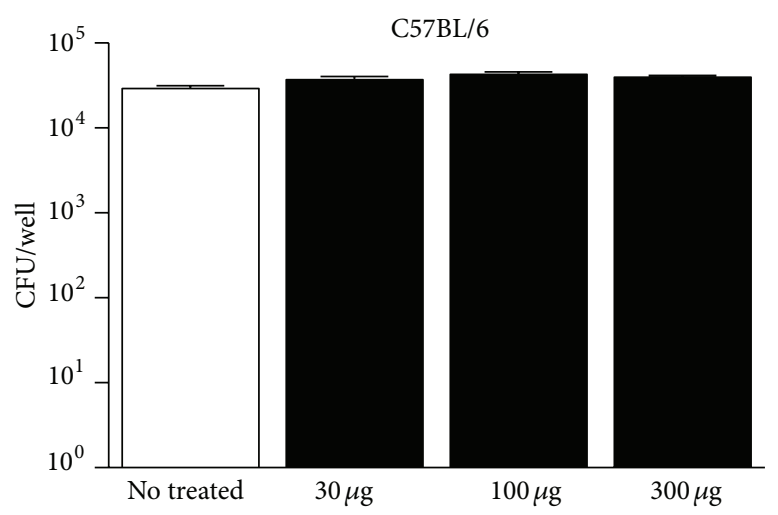

(b)

FIGURE 5: Propolis standardized extract (EPP-AF) reduces the IL-1 $\beta$ secretion in macrophages infected with L. pneumophila. (a) BMDMs from C57BL/6 mice were stimulated with LPS, pretreated or not with 30,100 , or $300 \mu \mathrm{g} / \mathrm{mL}$ of propolis extract, and infected with $L$. pneumophila during 12 hours. The supernatant was collected and levels of IL- $1 \beta$ were measured by ELISA assay. (b) BMDMs from C57BL/6 mice were pretreated or not with 30,100 , or $300 \mu \mathrm{g} / \mathrm{mL}$ of propolis extract and infected with L. pneumophila. Cultures were infected with $2 \times 10^{6}$ bacteria and further incubated for 12 hours. After this period, the cells were lysate with deionized water and the bacteria were plated on CYE agar for CFU determination. Data show average \pm standard deviation and an asterisk indicates a $P$ value of $<0.05$.

caspase-1 stain in macrophages treated with propolis and stimulated with LPS and nigericin (Figure 4). It is important to mention that LPS plus nigericin is a classic activator of the NLRP3 inflammasomes. The NLRP3 inflammasome has been implicated in response to a broad spectrum of infectious agents, including the bacterial pathogens as S. aureus, Vibrio cholerae, Escherichia coli, Neisseria gonorrhoeae, Chlamydia pneumoniae, and Citrobacter rodentium [59-63]; the fungal pathogens Candida albicans and Aspergillus fumigatus [6365]; viral pathogens such as influenza $A$, encephalomyocarditis virus, and vesicular stomatitis virus [66-68]; and the parasites Schistosoma mansoni and Dermatophagoides pteronyssinus [69]. Indeed, damage-associated molecular patterns (DAMPs) such as ATP, uric acid crystals, amyloid- $\beta$ fibrils, hyaluronan, and microbial toxins all activate NLRP3 [42, 70, 71]. We also confirm that propolis inhibits the NLRP3 inflammasome by using ATP and gramicidin as NLRP3 activators, and found the same results (Figures 4(b), 4(c), and 4(d)).

Finally, we investigated the regulatory effect of propolis in other inflammasome already described: the NLRC4 inflammasome. Unlike the NLRP3 inflammasome, NLRC4 is currently thought to respond to gram-negative bacterial components. So, we used the gram-negative bacterium $L$. pneumophila to activate the NLRC4 inflammasome and also verified the reduction on IL- $1 \beta$ secretion by infected cells that were treated with propolis (Figure 5(a)). Regardless the putative role of propolis in NLRC4 inflammasome, our data clearly demonstrate that Brazilian green propolis extract acts in regulating the IL-1 $\beta$ secretion by NLRP3 inflammasomes. This is a remarkable finding, since it was demonstrated that mutations in inflammasome-related genes, such as NLRP3 and NLRP1, are associated with autoimmune and autoinflammatory disorders [72]. Therefore, the use of natural products such as Brazilian propolis may open promising therapeutic strategies for the treatment of these severe chronic autoinflammatory diseases.

\section{Conclusion}

Altogether, these data indicate that Brazilian green propolis extract (EPP-AF) reduces the secretion of IL- $1 \beta$ by inhibiting the inflammasome activation, thus contributing to explain the previously anti-inflammatory activities of propolis. This specific regulation can be important once IL- $1 \beta$ mediates a variety of local and systemic responses to infection and autoinflammatory disorders such as gouty arthritis and type II diabetes.

\section{Acknowledgments}

The authors would like to thank Raul B. Ferreira from Apis Flora Company (Ribeirão Preto/SP-Brazil) for providing the propolis extract, for paper review and suggestions and Franciane Marquele Oliveira for English revision. This work was supported by FAPESP Grant 06/52867-4. J. I. Hori (2011/51023-5) and A. A. Berretta (2011/50089-2) are recipients of postdoctoral fellowships from FAPESP. D. B. Carrão (555276/2010-4) is technological development fellowship from CNPq/RHAE. D. S. Zamboni and G. H. Goldman are researchers fellows from $\mathrm{CNPq}$. 


\section{References}

[1] G. A. Burdock, "Review of the biological properties and toxicity of bee propolis (propolis)," Food and Chemical Toxicology, vol. 36, no. 4, pp. 347-363, 1998.

[2] A. H. Banskota, Y. Tezuka, and S. Kadota, "Recent progress in pharmacological research of propolis," Phytotherapy Research, vol. 15, no. 7, pp. 561-571, 2001.

[3] J. M. Sforcin, A. Fernandes Jr., C. A. M. Lopes, V. Bankova, and S. R. C. Funari, "Seasonal effect on Brazilian propolis antibacterial activity," Journal of Ethnopharmacology, vol. 73, no. 1-2, pp. 243-249, 2000.

[4] M. P. de Barros, J. P. B. Sousa, J. K. Bastos, and S. F. de Andrade, "Effect of Brazilian green propolis on experimental gastric ulcers in rats," Journal of Ethnopharmacology, vol. 110, no. 3, pp. 567-571, 2007.

[5] M. P. D. Barros, M. Lemos, E. L. Maistro et al., "Evaluation of antiulcer activity of the main phenolic acids found in Brazilian green propolis," Journal of Ethnopharmacology, vol. 120, no. 3, pp. 372-377, 2008.

[6] N. Paulino, S. R. L. Abreu, Y. Uto et al., "Anti-inflammatory effects of a bioavailable compound, artepillin C, in Brazilian propolis," European Journal of Pharmacology, vol. 587, no. 1-3, pp. 296-301, 2008.

[7] D. C. Tavares, G. R. M. Barcelos, L. F. Silva, C. C. C. Tonin, and J. K. Bastos, "Propolis-induced genotoxicity and antigenotoxicity in Chinese hamster ovary cells," Toxicology In Vitro, vol. 20, no. 7, pp. 1154-1158, 2006.

[8] J. M. Murad, S. A. Calvi, A. M. V. C. Soares, V. Bankova, and J. M. Sforcin, "Effects of propolis from Brazil and Bulgaria on fungicidal activity of macrophages against Paracoccidioides brasiliensis," Journal of Ethnopharmacology, vol. 79, no. 3, pp. 331-334, 2002.

[9] A. A. Berretta, A. P. Nascimento, P. C. Bueno, M. M. Vaz, and J. M. Marchetti, "Propolis standardized extract (EPP$\mathrm{AF}(\mathrm{R})$ ), an innovative chemically and biologically reproducible pharmaceutical compound for treating wounds," International Journal of Biological Sciences, vol. 8, no. 4, pp. 512-521, 2012.

[10] P. A. de Castro, M. Savoldi, D. Bonatto et al., "Molecular characterization of propolis-induced cell death in Saccharomyces cerevisiae," Eukaryotic Cell, vol. 10, no. 3, pp. 398-411, 2011.

[11] C. M. F. Reis, J. C. T. Carvalho, L. K. G. Caputo et al., "Atividade antiinflamatória, antiúlcera gástrica e toxicidade subcrônica do extrato etanólico de própolis," Revista Brasileira de Farmacognosia, vol. 9-10, no. 1, pp. 43-52, 2000.

[12] P. Broz and D. M. Monack, "Molecular mechanisms of inflammasome activation during microbial infections," Immunological Reviews, vol. 243, no. 1, pp. 174-190, 2011.

[13] A. Dunne, "Inflammasome activation: from inflammatory disease to infection," Biochemical Society Transactions, vol. 39, no. 2, pp. 669-673, 2011.

[14] L. Franchi, T. Eigenbrod, R. Muñoz-Planillo, and G. Nuñez, "The inflammasome: a caspase-1-activation platform that regulates immune responses and disease pathogenesis," Nature Immunology, vol. 10, no. 3, pp. 241-247, 2009.

[15] M. Lamkanfi, T. D. Kanneganti, L. Franchi, and G. Núñez, "Caspase-1 inflammasomes in infection and inflammation," Journal of Leukocyte Biology, vol. 82, no. 2, pp. 220-225, 2007.

[16] F. Martinon, K. Burns, and J. Tschopp, "The Inflammasome: a molecular platform triggering activation of inflammatory caspases and processing of proIL- $\beta$," Molecular Cell, vol. 10, no. 2, pp. 417-426, 2002.
[17] F. Martinon and J. Tschopp, "Inflammatory caspases and inflammasomes: master switches of inflammation," Cell Death and Differentiation, vol. 14, no. 1, pp. 10-22, 2007.

[18] E. A. Miao, I. A. Leaf, P. M. Treuting et al., "Caspase-1-induced pyroptosis is an innate immune effector mechanism against intracellular bacteria," Nature Immunology, vol. 11, no. 12, pp. 1136-1142, 2010.

[19] S. L. Fink and B. T. Cookson, "Caspase-1-dependent pore formation during pyroptosis leads to osmotic lysis of infected host macrophages," Cellular Microbiology, vol. 8, no. 11, pp. 1812$1825,2006$.

[20] T. N. Silveira and D. S. Zamboni, "Pore formation triggered by Legionella spp. is an Nlrc4 inflammasome-dependent host cell response that precedes pyroptosis," Infection and Immunity, vol. 78, no. 3, pp. 1403-1413, 2010.

[21] M. Lamkanfi and V. M. Dixit, "Inflammasomes: guardians of cytosolic sanctity," Immunological Reviews, vol. 227, no. 1, pp. 95-105, 2009.

[22] Z. L. Newman, M. P. Printz, S. Liu et al., "Susceptibility to anthrax lethal toxin-induced rat death is controlled by a single chromosome 10 locus that includes rNlrpl," PLoS Pathogens, vol. 6, no. 5, pp. 1-8, 2010.

[23] L. Franchi, A. Amer, M. Body-Malapel et al., "Cytosolic flagellin requires Ipaf for activation of caspase- 1 and interleukin $1 \beta$ in salmonella-infected macrophages," Nature Immunology, vol. 7, no. 6, pp. 576-582, 2006.

[24] T. Ren, D. S. Zamboni, C. R. Roy, W. F. Dietrich, and R. E. Vance, "Flagellin-deficient Legionella mutants evade caspase-1and Naip5-mediated macrophage immunity," PLoS Pathogens, vol. 2, no. 3, article e18, 2006.

[25] K. L. Lightfield, J. Persson, N. J. Trinidad et al., "Differential requirements for NAIP5 in activation of the NLRC4 inflammasome," Infection and Immunity, vol. 79, no. 4, pp. 1606-1614, 2011.

[26] F. S. Sutterwala, Y. Ogura, D. S. Zamboni, C. R. Roy, and R. A. Flavell, "NALP3: a key player in caspase-1 activation," Journal of Endotoxin Research, vol. 12, no. 4, pp. 251-256, 2006.

[27] V. Pétrilli, S. Papin, C. Dostert, A. Mayor, F. Martinon, and J. Tschopp, "Activation of the NALP3 inflammasome is triggered by low intracellular potassium concentration," Cell Death and Differentiation, vol. 14, no. 9, pp. 1583-1589, 2007.

[28] J. Wu, T. Fernandes-Alnemri, and E. S. Alnemri, "Involvement of the AIM2, NLRC4, and NLRP3 inflammasomes in caspase1 activation by Listeria monocytogenes," Journal of Clinical Immunology, vol. 30, no. 5, pp. 693-702, 2010.

[29] C. Bauer, P. Duewell, C. Mayer et al., "Colitis induced in mice with dextran sulfate sodium (DSS) is mediated by the NLRP3 inflammasome," Gut, vol. 59, no. 9, pp. 1192-1199, 2010.

[30] P. Duewell, H. Kono, K. J. Rayner et al., "NLRP3 inflammasomes are required for atherogenesis and activated by cholesterol crystals," Nature, vol. 464, no. 7293, pp. 1357-1361, 2010.

[31] M. H. Zaki, K. L. Boyd, P. Vogel, M. B. Kastan, M. Lamkanfi, and T. D. Kanneganti, "The NLRP3 inflammasome protects against loss of epithelial integrity and mortality during experimental colitis," Immunity, vol. 32, no. 3, pp. 379-391, 2010.

[32] J. P. B. de Sousa, P. C. P. Bueno, L. E. Gregório et al., "A reliable quantitative method for the analysis of phenolic compounds in Brazilian propolis by reverse phase high performance liquid chromatography," Journal of Separation Science, vol. 30, no. 16, pp. 2656-2665, 2007. 
[33] K. H. Berger and R. R. Isberg, "Two distinct defects in intracellular growth complemented by a single genetic locus in Legionella pneumophila," Molecular Microbiology, vol. 7, no. 1, pp. 7-19, 1993.

[34] F. M. Marim, T. N. Silveira, D. S. Lima Jr., and D. S. Zamboni, "A method for generation of bone marrow-derived macrophages from cryopreserved mouse bone marrow cells," PloS ONE, vol. 5, no. 12, Article ID e15263, 2010.

[35] A. P. Bazo, M. A. M. Rodrigues, J. M. Sforcin, J. L. V. de Camargo, L. R. Ribeiro, and D. M. F. Salvadori, "Protective action of propolis on the rat colon carcinogenesis," Teratogenesis Carcinogenesis and Mutagenesis, vol. 22, no. 3, pp. 183-194, 2002.

[36] S. Chirumbolo, "Propolis as anti-inflammatory and anti-allergic compounds: which role for flavonoids?" International Immunopharmacology, vol. 11, no. 9, pp. 1386-1387, 2011.

[37] G. Sartori, A. P. Pesarico, S. Pinton et al., "Protective effect of brown Brazilian propolis against acute vaginal lesions caused by herpes simplex virus type 2 in mice: involvement of antioxidant and anti-inflammatory mechanisms," Cell Biochemistry and Function, vol. 30, no. 1, pp. 1-10, 2011.

[38] E. Contassot, H. D. Beer, and L. E. French, "Interleukin-1, inflammasomes, autoinflammation and the skin," Swiss Medical Weekly, vol. 142, Article ID w13590, 2012.

[39] M. Banerjee and M. Saxena, "Interleukin-1 (IL-1) family of cytokines: role in type 2 diabetes," Clinica Chimica Acta, vol. 413, no. 15-16, pp. 1163-1170, 2012.

[40] O. Gross, C. J. Thomas, G. Guarda, and J. Tschopp, "The inflammasome: an integrated view," Immunological Reviews, vol. 243, no. 1, pp. 136-151, 2011.

[41] H. W. Stout-Delgado, S. E. Vaughan, A. C. Shirali, R. J. Jaramillo, and K. S. Harrod, "Impaired NLRP3 inflammasome function in elderly mice during influenza infection is rescued by treatment with nigericin," Journal of Immunology, vol. 188, no. 6, pp. 28152824, 2012.

[42] S. Mariathasan, D. S. Weiss, K. Newton et al., "Cryopyrin activates the inflammasome in response to toxins and ATP," Nature, vol. 440, no. 7081, pp. 228-232, 2006.

[43] A. J. McGahon, S. J. Martin, R. P. Bissonnette et al., "Chapter 9 the end of the (cell) line: methods for the study of apoptosis in vitro," Methods in Cell Biology, vol. 46, pp. 153-185, 1995.

[44] D. M. Zuckman, J. B. Hung, and C. R. Roy, "Pore-forming activity is not sufficient for Legionella pneumophila phagosome trafficking and intracellular growth," Molecular Microbiology, vol. 32, no. 5, pp. 990-1001, 1999.

[45] P. Smolewski, E. Bedner, L. Du et al., "Detection of caspases activation by fluorochrome-labeled inhibitors: multiparameter analysis by laser scanning cytometry," Cytometry, vol. 44, no. 1 , pp. 73-82, 2001.

[46] D. S. Zamboni, K. S. Kobayashi, T. Kohlsdorf et al., "The Bircle cytosolic pattern-recognition receptor contributes to the detection and control of Legionella pneumophila infection," Nature Immunology, vol. 7, no. 3, pp. 318-325, 2006.

[47] Y. Qu, S. Misaghi, K. Newton et al., "Pannexin-1 is required for ATP release during apoptosis but not for inflammasome activation," Journal of Immunology, vol. 186, no. 11, pp. 65536561, 2011.

[48] R. Allam, M. N. Darisipudi, K. V. Rupanagudi, J. Lichtnekert, J. Tschopp, and H. J. Anders, "Cutting edge: cyclic polypeptide and aminoglycoside antibiotics trigger IL- $1 \beta$ secretion by activating the NLRP3 inflammasome," Journal of Immunology, vol. 186, no. 5, pp. 2714-2718, 2011.
[49] E. A. Miao, D. P. Mao, N. Yudkovsky et al., "Innate immune detection of the type III secretion apparatus through the NLRC4 inflammasome," Proceedings of the National Academy of Sciences of the United States of America, vol. 107, no. 7, pp. 3076-3080, 2010.

[50] L. Franchi, J. Stoolman, T. D. Kanneganti, A. Verma, R. Ramphal, and G. Núñez, "Critical role for Ipaf in Pseudomonas aeruginosa-induced caspase-1 activation," European Journal of Immunology, vol. 37, no. 11, pp. 3030-3039, 2007.

[51] L. Franchi, C. McDonald, T. D. Kanneganti, A. Amer, and G. Núñez, "Nucleotide-binding oligomerization domainlike receptors: intracellular pattern recognition molecules for pathogen detection and host defense," Journal of Immunology, vol. 177, no. 6, pp. 3507-3513, 2006.

[52] D. J. Newman and G. M. Cragg, "Natural products as sources of new drugs over the last 25 years," Journal of Natural Products, vol. 70, no. 3, pp. 461-477, 2007.

[53] V. Bankova, "Chemical diversity of propolis and the problem of standardization," Journal of Ethnopharmacology, vol. 100, no. 12, pp. 114-117, 2005.

[54] A. Salatino, E. W. Teixeira, G. Negri, and D. Message, "Origin and chemical variation of Brazilian propolis," Evidence-Based Complementary and Alternative Medicine, vol. 2, no. 1, pp. 3338, 2005.

[55] S. Ansorge, D. Reinhold, and U. Lendeckel, "Propolis and some of its constituents down-regulate DNA synthesis and inflammatory cytokine production but induce TGF- $\beta 1$ production of human immune cells," Zeitschrift fur Naturforschung C, vol. 58, no. 7-8, pp. 580-589, 2003.

[56] A. A. Korish and M. M. Arafa, "Propolis derivatives inhibit the systemic inflammatory response and protect hepatic and neuronal cells in acute septic shock," Brazilian Journal of Infectious Diseases, vol. 15, no. 4, pp. 332-338, 2011.

[57] J. J. Song, J. G. Cho, S. J. Hwang, C. G. Cho, S. W. Park, and S. W. Chae, "Inhibitory effect of caffeic acid phenethyl ester (CAPE) on LPS-induced inflammation of human middle ear epithelial cells," Acta Oto-Laryngologica, vol. 128, no. 12, pp. 1303-1307, 2008.

[58] C. A. Dinarello, "Interleukin-1 $\beta$ and the autoinflammatory diseases," The New England Journal of Medicine, vol. 360, no. 23, pp. 2467-2470, 2009.

[59] J. A. Duncan, X. Gao, M. T. H. Huang et al., "Neisseria gonorrhoeae activates the proteinase cathepsin B to mediate the signaling activities of the NLRP3 and ASC-containing inflammasome," Journal of Immunology, vol. 182, no. 10, pp. 64606469, 2009.

[60] X. He, S. Mekasha, N. Mavrogiorgos, K. A. Fitzgerald, E. Lien, and R. R. Ingalls, "Inflammation and fibrosis during Chlamydia pneumoniae infection is regulated by IL-1 and the NLRP3/ASC inflammasome," Journal of Immunology, vol. 184, no. 10, pp. 5743-5754, 2010.

[61] N. Kayagaki, S. Warming, M. Lamkanfi et al. et al., "Noncanonical inflammasome activation targets caspase-11," Nature, vol. 479, no. 7371, pp. 117-121, 2011.

[62] C. Toma, N. Higa, Y. Koizumi et al., "Pathogenic Vibrio activate NLRP3 inflammasome via cytotoxins and TLR/nucleotidebinding oligomerization domain-mediated NF- $\kappa \mathrm{B}$ signaling," Journal of Immunology, vol. 184, no. 9, pp. 5287-5297, 2010.

[63] O. Gross, H. Poeck, M. Bscheider et al., "Syk kinase signalling couples to the Nlrp3 inflammasome for anti-fungal host defence," Nature, vol. 459, no. 7245, pp. 433-436, 2009. 
[64] A. G. Hise, J. Tomalka, S. Ganesan et al., "An essential role for the NLRP3 inflammasome in host defense against the human fungal pathogen Candida albicans," Cell Host and Microbe, vol. 5, no. 5, pp. 487-497, 2009.

[65] S. Joly, N. Ma, J. J. Sadler, D. R. Soll, S. L. Cassel, and F. S. Sutterwala, "Cutting edge: Candida albicans hyphae formation triggers activation of the Nlrp3 inflammasome," Journal of Immunology, vol. 183, no. 6, pp. 3578-3581, 2009.

[66] I. C. Allen, M. A. Scull, C. B. Moore et al., "The NLRP3 inflammasome mediates in vivo innate immunity to influenza A virus through recognition of viral RNA," Immunity, vol. 30, no. 4, pp. 556-565, 2009.

[67] T. Ichinohe, I. K. Pang, and A. Iwasaki, "Influenza virus activates inflammasomes via its intracellular M2 ion channel," Nature Immunology, vol. 11, no. 5, pp. 404-410, 2010.

[68] J. V. Rajan, D. Rodriguez, E. A. Miao, and A. Aderem, "The NLRP3 inflammasome detects encephalomyocarditis virus and vesicular stomatitis virus infection," Journal of Virology, vol. 85, no. 9, pp. 4167-4172, 2011.

[69] M. Ritter, O. Gross, S. Kays et al., "Schistosoma mansoni triggers Dectin-2, which activates the Nlrp3 inflammasome and alters adaptive immune responses," Proceedings of the National Academy of Sciences of the United States of America, vol. 107, no. 47, pp. 20459-20464, 2010.

[70] A. Halle, V. Hornung, G. C. Petzold et al., “The NALP3 inflammasome is involved in the innate immune response to amyloid$\beta$," Nature Immunology, vol. 9, no. 8, pp. 857-865, 2008.

[71] F. Martinon, V. Pétrilli, A. Mayor, A. Tardivel, and J. Tschopp, "Gout-associated uric acid crystals activate the NALP3 inflammasome," Nature, vol. 440, no. 7081, pp. 237-241, 2006.

[72] K. Shinkai, T. H. McCalmont, and K. S. Leslie, "Cryopyrinassociated periodic syndromes and autoinflammation," Clinical and Experimental Dermatology, vol. 33, no. 1, pp. 1-9, 2008. 


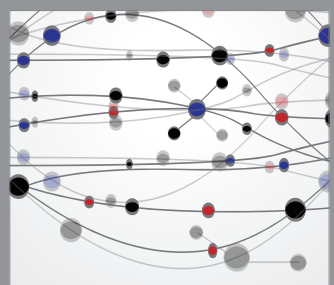

The Scientific World Journal
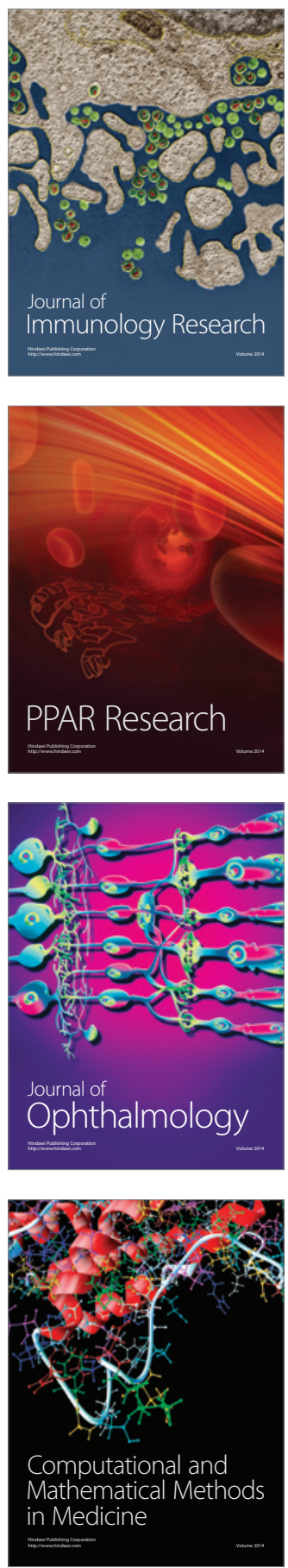

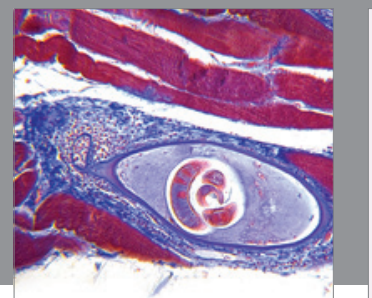

Gastroenterology

Research and Practice
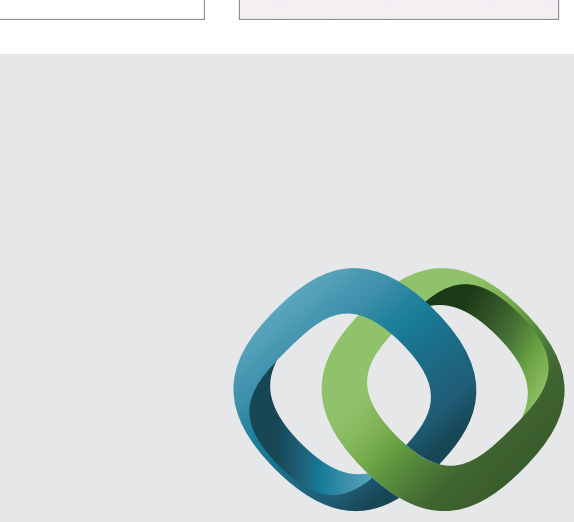

\section{Hindawi}

Submit your manuscripts at

http://www.hindawi.com
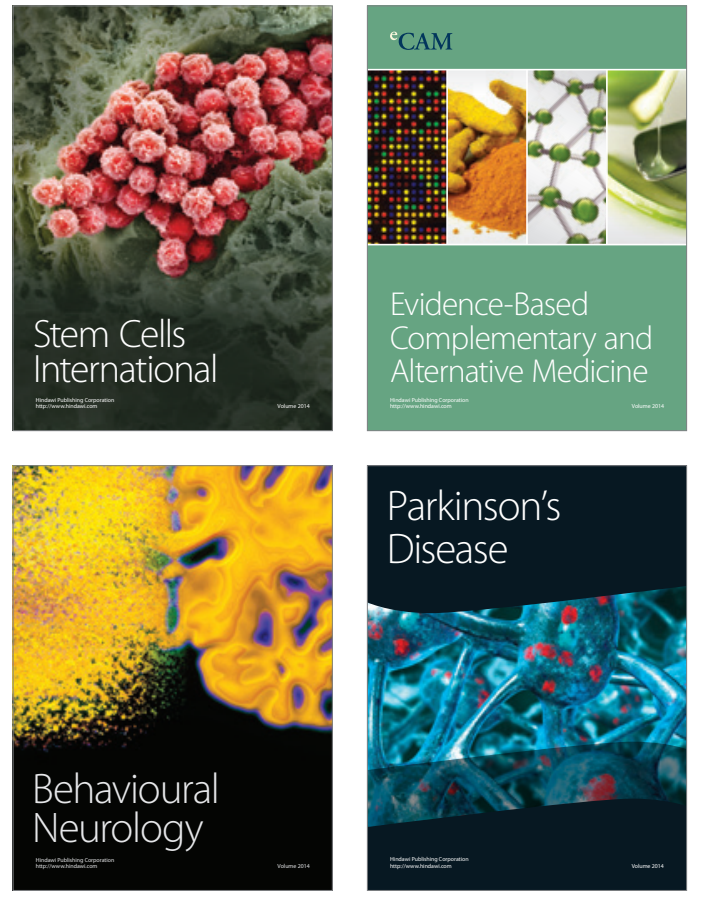
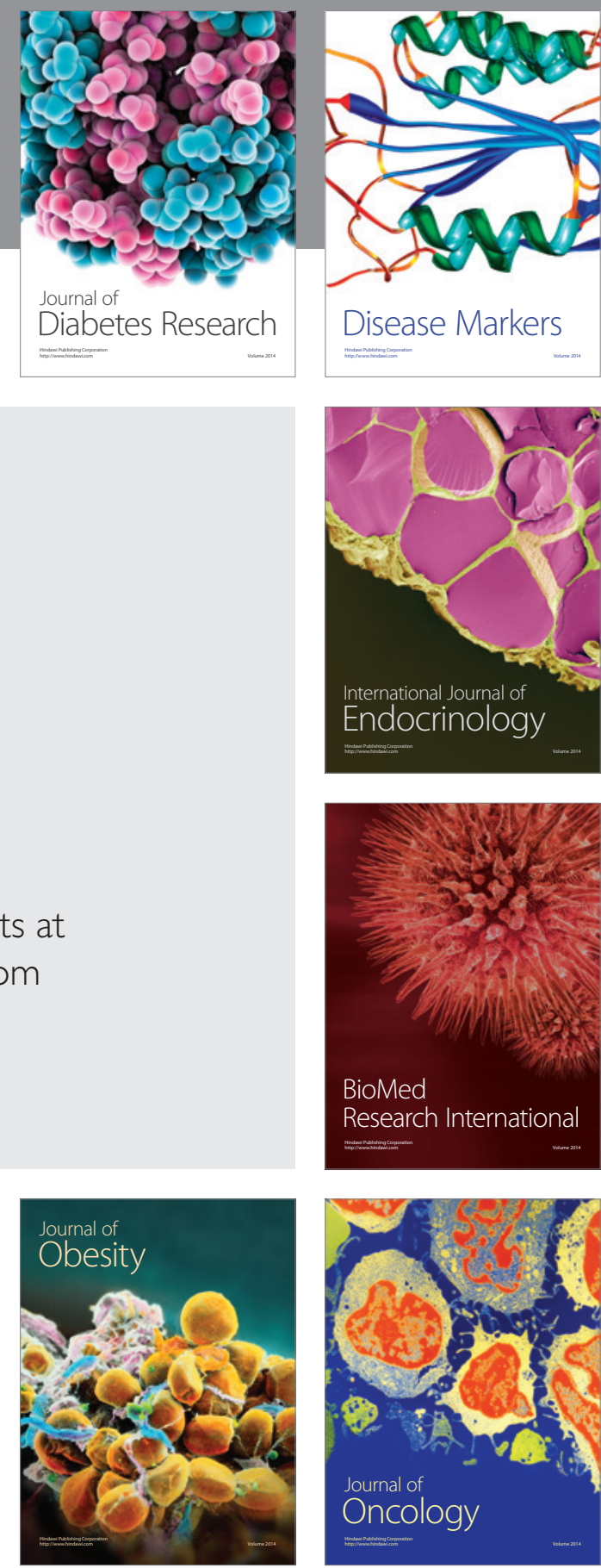

Disease Markers
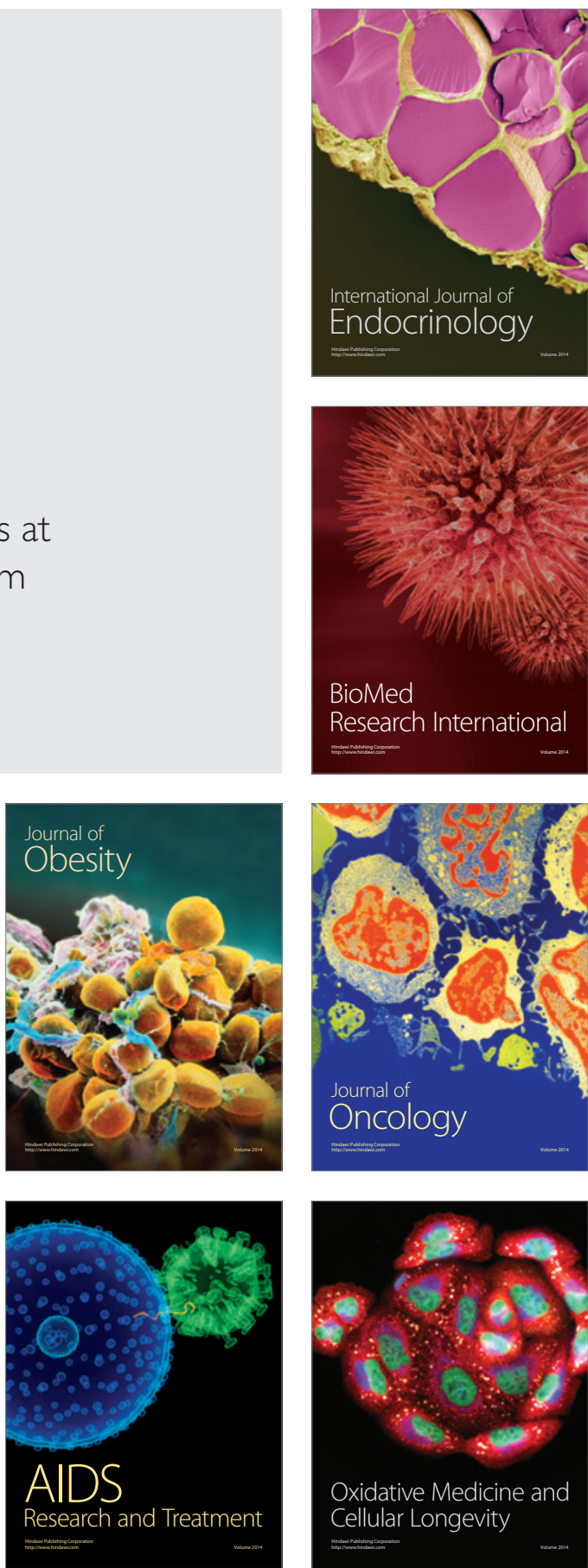